\title{
Assessment of the preventive effects of Silybum marianum (L.) Gaertn. seeds hydroethanolic extract and silymarin on complete Freund's adjuvant-induced arthritis in wistar rats
}

\author{
Marwa S. Saber*, Hanaa I. Fahim*, Osama M. Ahmed*, Noha A. Ahmed* and Mohammed Abdel-Gabbar** \\ *Physiology Division, Zoology Department, Faculty of Science, Beni-Suef University, P.O. Box 62521, Beni-Suef, Egypt. \\ **Biochemistry Department, Faculty of Science, Beni-Suef University, P.O. Box 62521, Beni-Suef, Egypt.
}

\section{Article Info}

Article history

Received 8 August 2020

Revised 26 September 2020

Accepted 29 September 2020

Published online 30 December 2020

Keywords

CFA

Cytokines

Milk thistle

Rheumatoid arthritis

Silymarin

Silybum marianum (L.) Gaertn

\begin{abstract}
This study aims to evaluate the antiarthritic activity of milk thistle and silymarin in complete Freund's adjuvant (CFA)-induced arthritis in male rats. Rheumatoid arthritis was induced by injection of $0.2 \mathrm{ml}$ of CFA into the right hind leg at two consecutive days. These rats were treated with milk thistle seeds hydroethanolic extract (MTHE) $(100 \mathrm{mg} / \mathrm{kg} \mathrm{b} . w \mathrm{t} / \mathrm{day})$ and silymarin $(100 \mathrm{mg} / \mathrm{kg} \mathrm{b}$.wt/day) for 9 and 18 days. MTHE and silymarin ameliorated the CFA-induced increase in paw circumference, serum RF, TNF- $\alpha$, IL-1 $\beta$, IL-17 and PGE2, and liver lipid peroxidation. They also corrected the CFA-induced decrease in serum IL-4 level and antioxidant defense system. Moreover, both treatments reduced the synovial hyperplasia and inflammation in ankle joints as well as lymphoblastic necrosis and mitotic figures in spleen and thymus of arthritic rats. In conclusion, MTHE and silymarin have antiarthritic efficacies which may be mediated via their anti-inflammatory and antioxidant properties in CFA-induced arthritic rats.
\end{abstract}

\section{Introduction}

Rheumatoid arthritis (RA) is a chronic inflammatory autoimmune disease which is characterized by synovial hyperplasia, synovitis, and tissue invasion which result in stiffness, swelling, and pain leading to joint dysfunction (Subramoniam et al., 2013). It ranges from 0.3 and $1 \%$ throughout the world. Women are more affected than man by three times (Carmona et al., 2010).

In RA, there is a complex interaction between genotypes, environmental factors, and lifestyle factors (Too et al., 2012). T helper 1 (Th1)/T helper 2 (Th2)/T helper 17 (Th17) pattern plays a dominant role in the initiation and propagation of RA (Ahmed et al., 2017; Ahmed et al., 2018a and c). Cluster differentiation (CD4 $\left.{ }^{+}\right)$ $\mathrm{T}$ lymphocytes is functionally categorized into Th1 cells which secrete pro-inflammatory cytokines: interlukin-2 (1L-2), IL-12, tumor necrosis factor alpha (TNF- $\alpha)$, L-1 $\beta$, IL-6, IL- 8 and interferon gamma (IFN- $\gamma)$, while Th2 cells secrete anti-inflammatory: cytokine: IL-1 receptor antagonist, IL-4, IL-5, IL-10 and IL-13 (Luckheeram et al., 2012). Th17 cells secrete another proinflammatory cytokine: IL-17 (Ahmed et al., 2018c). The elevation in the pro-inflammatory cytokines' levels and the decrease in the anti-inflammatory cytokines' levels reflect the dominance of Th1 above Th2 (Ahmed et al., 2015).

Corresponding author: Dr. Mohammed Abdel-Gabbar Associate Professor, Biochemistry Department, Faculty of Science, Beni-Suef University, P.O. Box 62521, Beni-Suef, Egypt. E-mail: hhmgabar@yahoo.com; hhmgabar@science.bsu.edu.eg Tel.: +20-11-46989822

Copyright (c) 2020 Ukaaz Publications. All rights reserved.

Email: ukaaz@yahoo.com; Website: www.ukaazpublications.com
TNF- $\alpha$ and IL-1 $\beta$ increase fibroblasts proliferation, stimulate prostaglandin E2 (PGE2) production and enhance other cytokines expression and collagen synthesis by synovial cells which is involved in destruction of cartilage and bone (Dayer and Fenner, 1992). RA is thought to be mediated by Th1 cells but Th17 now have fundamental role in disease pathogenesis. IL-17 has a role in pathogenesis of several autoimmune diseases including RA(Ganesan and Rasool, 2019).

Now, collagen type II-induced arthritis (CIA) in rats and mice and adjuvant induced arthritis (AIA) in rats are the most common arthritis models in academia and industry (Bolon et al., 2011).

Oxidative stress is considered to be an important determinant in RA pathogenicity since oxygen free radicals are main factors associated with tissue destruction (Yoo et al., 2016). Within painful or inflamed joints, neutrophils, chondrocytes, and macrophages can produce reactive oxygen species (ROS) that are liable for T-cells stimulation and synovial inflammation (Umar et al., 2012).

The conventional treatments of RA with anti-CD20 therapy, TNF- $\alpha$ antagonists, and non-steroidal anti-inflammatory drugs (NSAIDs) exhibited some success but their toxicity, higher cost, and adverse effects created limitations for them (Curtis and Singh, 2011). Hence, there is a persistent search for effective and safer antiarthritic agents derived from natural sources (Subramoniam, 2016).

The stunning gift of nature is medicinal plants, although it depends on the way these plants are utilized by the human (Das et al., 2019). Various herbaceous plants such as G. glabra, C. sinensis, 
C. reticulata, $M$. paradisiaca and $S$. marinum and their active ingredients were proofed to be effective against various diseases (El Mageed et al., 2009; Ali et al., 2020; Abdel Aziz et al., 2020). Milk thistle or Silybum marianum (L.) Gaertn (S. marianum), a member of the Asteraceae family, is annual or biennial herbaceous plant. It has been utilized in traditional medicine for over 2000 years and was known for its liver protecting properties since ancient Greek civilization (Ionut et al., 2018). S. marianum seeds contain plentiful of phytochemicals like tocopherol that shows antioxidant activities and silymarin that has both antioxidant and antiinflammatory properties (Abenavoli et al., 2018).

Additionally, three isomeric flavonolignans were extracted from milk thistle seeds; silibinin (silybin), silychristin, and silidianin. All collectively are known as silymarin (Ionut et al., 2018). Silymarin has anti-inflammatory, antiangiogenic, antimetastatic, and immunomodulatory activities in various structures and pathways of the cell. Silymarin is also with a strong antioxidant impact and free radical scavenger by different mechanisms (Esmaeil et al., 2017).

Silymarin isolated from $S$. marianum have been reported by various publications to have anti-iflammatory and antioxidant properties in different experimental conditions (Sharifi-Rigi and Heidarian, 2019; Ahmed et al., 2016). However, very rare publications, that assess the effects of silymarin on experimentally induced rheumatoid arthritis, were reported.

Therefore, the purpose of this study is to assess the antiarthritic activities and to suggest the mechanism of action of milk thistle seeds hydroethanolic extract (MTHE) and silymarin as natural products in CFA-induced arthritis in male wistar rats.

\section{Materials and Methods}

\subsection{Experimental animals}

The experimental animals used in the present investigation are male Wistar rats, of body weights ranging from 160-180 g and ageing 10-12 weeks. To exclude any intercurrent infections, the rats were observed for two weeks before the experiment initiation. The animals were kept at normal atmospheric temperature $\left(25 \pm 5^{\circ} \mathrm{C}\right)$ and received water and standard balanced diet ad libitum.

\subsection{Chemicals}

All chemicals were of analytical grade. CFA, a suspension of heat killed mycobacterium tuberculosis in mineral oil, CFA was obtained from Sigma Chemical Company (St. Louis, MO 63178, USA)

\subsection{Plant material and silymarin}

Milk thistle (Silybum marianum (L.) Gaertn) dried seeds were obtained from Harraz for Food Industry and Natural Products, Cairo, Egypt (http://www.harraznatural.com/ar/about-us.php). The plant seeds were authenticated by Professor Sameh F. Abouzid, Beni-Suef University, Egypt. Plant sample was deposited in the Herbarium of Botany Department of Faculty of Science, Beni-Suef University, Egypt (Voucher number: BNSU-1372). By using the NCBI taxonomy database, Taxonomy ID: 92921 (NCBI:txid92921) (https://www.ncbi.nlm.nih.gov/Taxonomy/). Silymarin was supplied as a gift from Professor Sameh F. Abouzid.

\subsubsection{Preparation of hydroethanolic extract and doses of milk} thistle

Half kilogram of dried milk thistle seeds was grinded, soaked in $70 \%$ ethanol for $48 \mathrm{~h}$, filtrated, and the filtrate was concentrated under vacuum by using a rotary evaporator to a viscous semi-solid aliquot. Milk thistle hydroethanolic extract (MTHE) was dissolved in $1 \%$ carboxymethyl cellulose (CMC) at $20 \%$ concentration and it was daily administered at dose level of $100 \mathrm{mg} / \mathrm{kg} \mathrm{b.w./day} \mathrm{(Hikal}$ et al., 2018) by oral gavage for 9 or 18 days.

\subsubsection{Doses preparation of silymarin}

Silymarin was dissolved in $1 \%$ CMC solution at concentration $20 \%$ and were given at a dose level of $100 \mathrm{mg} / \mathrm{kg}$ b.w. (Hashem et al., 2016) daily for 9 or 18 days by oral administration. In animal studies, silymarin has been reported to be nontoxic and symptom free with the maximum oral doses of 2500 and $5000 \mathrm{mg} / \mathrm{kg}$ (Karimi et al., 2011).

\subsection{Induction of AIA}

RA was induced in male rats by subcutaneous injection of double dose of CFA at two successive days $(0.1 \mathrm{ml} /$ day $)$ into right hind leg foot paw according to Ahmed et al. (2018b).

\subsection{Animal grouping}

Animals were allocated into four groups (6 rats for each group) designed as follows:

Group 1 (Normal control group): It included normal rats that received the equivalent volume of $1 \% \mathrm{CMC}$ by oral gavage for 9 and 18 days.

Group 2 (Arthritic control group): The animals within this group were subcutaneously injected with double dose of CFA for two successive days and were given the equivalent volume of the vehicle $(\mathrm{CMC})(1 \% \mathrm{w} / \mathrm{v})$ by oral gavage daily for 9 or 18 days.

Group 3 (Arthritic group treated with MTHE): The rats in this group were subcutaneously injected with CFA as group 2 and were daily treated with MTHE dissolved in $1 \% \mathrm{CMC}$ at dose of $100 \mathrm{mg} / \mathrm{kg}$ b.w. by oral gavage for 9 or 18 days.

Group 4 (Arthritic group treated with silymarin): The rats of this group were subcutaneously injected with CFA as group 2 and group 3 and were treated daily with silymarin dissolved in $1 \%$ $\mathrm{CMC}$ at dose of $100 \mathrm{mg} / \mathrm{kg}$ b.w. by oral gavage for 9 or 18 days.

At the end of the experiment, right hind paw circumference (RHPC) was measured. Then, blood samples were collected from the jugular vein. From each rat, part of blood was collected on ethylene diamine tetra-acetic acid (EDTA) solution (10\%) for determination of total leucocyte count (TLC) and differential leucocyte count (DLC). Another part was collected in gel tubes without EDTA to separate serum by centrifugation at $3000 \mathrm{rpm}$ for $15 \mathrm{~min}$ for determination of biochemical and physiological parameters like rheumatoid factor (RF), pro-inflammatory and anti-inflammatory cytokines. After cervical dislocation, tissue samples including liver, ankle joint, spleen and thymus were immediately excised for biochemical as well as for histopathological studies. 
2.6 Detection of RHPC as an indicator of paw odema $(\mathrm{cm})$

RHPC just above tarsal pad was measured as a marker of swelling rate and odema in all groups. It was measured by wrapping a string around the paw, and then the length of the string was measured with a ruler. The measurements were taken after 9 or 18 days after CFA injection (Olajide et al., 2009).

\subsection{Determination of serum RF level $(\mathrm{U} / \mathrm{ml})$}

RF level in serum was accomplished by using rat RF ELISA kit obtained from R and D (R\&D Systems, Inc., Minneapolis, MN, USA).

\subsection{Detection of TLC and DLC (cell/ $/ \mathrm{mm} 3) \times 10^{3}$}

TLC was determined by Neubauer slide using Turk $\times$ s solution which is composed of gentian violet and $1 \%$ acetic acid (Miale, 1972). DLC was carried out according to method of Gallagher et al. (1972) by using giemsa stain.

\subsection{Detection of serum cytokines $(\mathrm{Pg} / \mathrm{ml})$}

The levels of serum inflammatory cytokines, TNF- $\alpha$, IL-1 $\beta$, IL-17 and PGE2, and serum anti-inflammatory cytokine, IL-4, levels were determined using specific ELISA kits obtained from R and D systems (R\&D Systems, Inc., Minneapolis, MN, USA) according to the manufacturer's instructions.

\subsection{Detection of liver oxidative stress and antioxidant defense markers}

Liver of each animal excised after dissection and perfused in isotonic sterile saline $(\mathrm{NaCl} 0.9 \%)$. Half gram of liver of each rat was homogenized in $5 \mathrm{ml}$ isotonic saline. Liver glutathione (GSH) (nmol/ $100 \mathrm{mg}$ tissue) and lipid peroxides (LPO) (nmole MDA/100 gm tissue/hour) levels besides liver glutathione peroxidase (GPx) (mU/ $100 \mathrm{gm}$ tissue), glutathione-S-transferase (GST) (U/g tissue) and, superoxide dismutase (SOD) (U/g tissue) activities were measured as described before (Ahmed et al., 2018c).

\subsection{Histopathological investigation}

After dissection, ankle joint, spleen and thymus were immediately excised and were fixed in neutral buffered formalin (NBF) (10\%) for 2 days. Then, the bones of ankle joints were decalcified in $10 \%$ EDTA for a period of (2-3) weeks while the fixed spleen and thymus as well as decalcified ankle were processed for blocking, sectioning and staining with hematoxylin and eosin (H\&E) according to method of Banchroft et al. (1996). Processing of specimens was done by washing with tap water and alcohol serial dilution for dehydration. Then, specimens were washed and inserted in paraffin in warm air oven for one day. The obtained sections were mounted on glass slides and stained with $\mathrm{H}$ and $\mathrm{E}$ stain and then examined by histopathologist.

\subsection{Statistical analysis}

Statistical analysis of data was performed by using one-way and two-way analysis of variance (ANOVA) by using PC-STAT, University of Georgia. Then, least significant difference (LSD) analysis was done to compare various groups with each other (Rao et al., 1985). Results were expressed as Mean \pm SE. Values of $p<0.05$ and $p<0.01$ were significantly and highly significantly different while, values of $p>0.05$ were considered non-significant.

\section{Results}

A highly significant $(p<0.01)$ increase in RHPC of CFA-induced arthritic rats was observed after 9 and 18 days of CFA injection. The treatment of arthritic rats with MTHE induced a highly significant $(p<0.01)$ decrease of RHPC after 9 days and a nonsignificant $(p>0.05)$ decrease after 18 days as compared with the corresponding normal control. Similarly, the treatment of arthritic rats with silymarin induced a highly significant $(p<0.01)$ decrease of RHPC after 9 and 18 days as compared with the corresponding arthritic controls. (Table 1).

CFA injection to normal rats produced a highly significant $(p<0.01)$ increase in serum RF level after 9 and 18 days. The treatment of arthritic rats with MTHE and silymarin induced a significant improvement $(p<0.01)$ of the elevated RF level after 9 and 18 days (Table 1).

TLC of CFA-induced arthritic rats exhibited a highly significant $(p<0.01)$ increase as compared to normal rats after 9 and 18 days of CFA injection. The treatment of arthritic rats with MTHE and silymarin produced a highly significant $(p<0.01)$ decrease of the TLC after 9 days and 18 days of CFA injection (Table 1).

Neutrophils, lymphocytes, and monocytes counts of CFA-induced arthritic rats showed a highly significant $(p<0.01)$ increases after 9 and 18 days of CFA injection. The treatment of arthritic rats with MTHE or silymarin induced a highly significant $(p<0.01)$ decreases of their counts after 9 and 18 days but produced a significant decrease in lymphocyte count $(p<0.05)$ after 18 days (Table 2$)$.

The CFA-induced arthritic rats exhibited a highly significant $(p<0.01)$ increase in serum TNF- $\alpha$, IL-1 $\beta$, IL-17 and PGE2 levels and a highly significant $(p<0.01)$ decrease in serum IL-4 level after 9 and 18 days as compared with normal control. The treatment of arthritic rats with MTHE or silymarin induced a highly significant $(p<0.01)$ decrease of the elevated levels of serum TNF- $\alpha$, IL- $1 \beta$, IL-17 and PGE2 and a highly significant $(p<0.01)$ increase in IL-4 level after 9 and 18 days in comparison with arthritic control (Table 3 ).

LPO (expressed by the MDA content) in liver of rats injected with CFA showed a highly significant $(p<0.01)$ increase after 9 and 18 days. The treatment of arthritic rats with MTHE and silymarin induced a highly significant $(p<0.01)$ decrease after 9 and 18 days (Table 4).

GPx, GST, SOD activities besides GSH content in liver of male rats exhibited a significant decrease after 9 or 18 days of CFA injection. The treatment of arthritic rats with MTHE or silymarin for 9 and 18 days induced a highly significant elevation of the GPx, (GST, 9 days) activities $(p<0.01)$ (Table 4$)$.

The treatment of arthritic rats with silymarin, on the other hand, induced a non-significant ( $p>0.05)$ increase of GST activity after 9 and 18 days as compared with arthritic control (Table 4).

The treatment of arthritic rats with MTHE and silymarin for 9 and 18 days induced a non-significant $(p>0.05)$ change of the SOD activity (Table 4). 
Table 1: Effect of MTHE and silymarin on right hind paw circumference, serum RF level and TLC in arthritic rats

\begin{tabular}{|c|c|c|c|c|c|c|}
\hline \multirow[b]{2}{*}{ Group } & \multicolumn{2}{|c|}{ Right hind paw circumference $(\mathrm{cm})$} & \multicolumn{2}{|c|}{ RF $(\mathrm{U} / \mathrm{ml})$} & \multicolumn{2}{|c|}{ TLC $\left(\right.$ cell $\left./ \mathrm{mm}^{3}\right) \times 10^{3}$} \\
\hline & 9 days & 18 days & 9 days & 18 days & 9 days & 18 days \\
\hline Normal control & $2.00 \pm 0.03^{\mathrm{e}}$ & $2.05 \pm 0.02^{\mathrm{e}}$ & $14.77 \pm 0.95^{\mathrm{e}}$ & $16.73 \pm 0.37^{\mathrm{e}}$ & $6.50 \pm 0.66^{\mathrm{e}}$ & $7.10 \pm 0.27^{\mathrm{e}}$ \\
\hline Arthiritic control & $3.40 \pm 0.14^{\mathrm{a}}$ & $2.92 \pm 0.08^{\mathrm{b}}$ & $35.36 \pm 0.84^{\mathrm{b}}$ & $51.76 \pm 2.95^{\mathrm{a}}$ & $15.32 \pm 1.13^{\mathrm{a}}$ & $14.33 \pm 0.41^{\mathrm{ab}}$ \\
\hline Arthiritic treated with MTHE & $2.57 \pm 0.06^{\mathrm{cd}}$ & $2.78 \pm 0.05^{\text {bc }}$ & $18.33 \pm 0.88^{\mathrm{de}}$ & $30.60 \pm 1.26^{\mathrm{bc}}$ & $7.43 \pm 0.81^{\mathrm{e}}$ & $12.63 \pm 0.12^{\mathrm{bc}}$ \\
\hline Arthiritic treated with silymarin & $2.58 \pm 0.05^{\text {cd }}$ & $2.54 \pm 0.10^{\mathrm{d}}$ & $22.90 \pm 2.22^{\mathrm{d}}$ & $29.10 \pm 3.61^{\mathrm{c}}$ & $9.33 \pm 0.56^{\mathrm{d}}$ & $10.97 \pm 0.72^{\text {cd }}$ \\
\hline LSD at $5 \%$ level & \multicolumn{2}{|c|}{0.22} & \multicolumn{2}{|c|}{5.67} & \multicolumn{2}{|c|}{1.89} \\
\hline LSD at $1 \%$ level & \multicolumn{2}{|c|}{0.29} & \multicolumn{2}{|c|}{7.63} & \multicolumn{2}{|c|}{2.55} \\
\hline
\end{tabular}

- Data are expressed as Mean \pm SE. Number of animals in each group is six.

- Within each column, means, which have different superscript letter, are significantly different at $p<0.05$.

Table 2: Effect of MTHE and silymarin on neutrophil, lymphocyte, monocyte and eosinophil counts

\begin{tabular}{|c|c|c|c|c|c|c|c|c|}
\hline \multirow[b]{2}{*}{ Group } & \multicolumn{2}{|c|}{$\begin{array}{l}\text { Neutrophil count } \\
\left(\text { cell } / \mathrm{mm}^{3}\right) \times 10^{3}\end{array}$} & \multicolumn{2}{|c|}{$\begin{array}{l}\text { Lymphocyte count } \\
\quad\left(\text { cell } / \mathrm{mm}^{3}\right) \times 10^{3}\end{array}$} & \multicolumn{2}{|c|}{$\begin{array}{l}\text { Monocyte count } \\
\left(\text { cell } / \mathrm{mm}^{3}\right) \times 10^{3}\end{array}$} & \multicolumn{2}{|c|}{$\begin{array}{l}\text { Eosinophil count } \\
\left(\text { cell } / \mathrm{mm}^{3}\right) \times 10^{3}\end{array}$} \\
\hline & 9 days & 18 days & 9 days & 18 days & 9 days & 18 days & 9 days & 18 days \\
\hline Normal control & $2.04 \pm 0.06^{b}$ & $2.20 \pm 0.14^{\mathrm{b}}$ & $3.99 \pm 0.05^{\mathrm{b}}$ & $4.42 \pm 0.16^{\mathrm{d}}$ & $0.19 \pm 0.02^{\mathrm{c}}$ & $0.21 \pm 0.09^{\mathrm{c}}$ & $0.11 \pm 0.02^{\mathrm{d}}$ & $0.166 \pm 0.011^{\mathrm{cd}}$ \\
\hline Arthiritic control & $4.26 \pm 042^{\mathrm{a}}$ & $3.71 \pm 0.05^{\mathrm{a}}$ & $9.97 \pm 0.30^{\mathrm{a}}$ & $10.42 \pm 0.30^{\mathrm{a}}$ & $0.95 \pm 0.18^{\mathrm{a}}$ & $0.70 \pm 0.081^{b}$ & $0.28 \pm 0.02^{\mathrm{bc}}$ & $0.32 \pm 0.06^{\mathrm{a}}$ \\
\hline Arthiritic treated with MTHE & $1.77 \pm 0.21^{\mathrm{b}}$ & $2.19 \pm 0.10^{\mathrm{b}}$ & $6.35 \pm 0.25^{c}$ & $9.85 \pm 0.05^{b}$ & $0.20 \pm 0.03^{\mathrm{c}}$ & $0.26 \pm 0.03^{\mathrm{c}}$ & $0.20 \pm 0.03^{\mathrm{cd}}$ & $0.24 \pm 0.07^{\mathrm{abc}}$ \\
\hline Arthiritic treated with silymarin & $2.27 \pm 0.07^{b}$ & $1.89 \pm 0.03^{b}$ & $6.87 \pm 0.02^{c}$ & $9.52 \pm 0.02^{b}$ & $0.29 \pm 0.03^{c}$ & $0.33 \pm 0.04^{\mathrm{c}}$ & $0.22 \pm 0.01^{\mathrm{bc}}$ & $0.301 \pm 0.05^{\mathrm{ab}}$ \\
\hline LSD at $5 \%$ level & \multicolumn{2}{|c|}{0.706} & \multicolumn{2}{|c|}{0.535} & \multicolumn{2}{|c|}{0.217} & \multicolumn{2}{|c|}{0.102} \\
\hline LSD at $1 \%$ level & \multicolumn{2}{|c|}{0.951} & \multicolumn{2}{|c|}{0.721} & \multicolumn{2}{|c|}{0.292} & \multicolumn{2}{|c|}{0.138} \\
\hline
\end{tabular}

- Data are expressed as Mean \pm SE. Number of animals in each group is six.

- Within each column, means, which have different superscript letter, are significantly different at $p<0.05$.

Table 3: Effect of MTHE and silymarin on serum TNF- $\alpha$, IL-1 $\beta$, IL-17, PGE2 and IL-4 levels in arthritic rats

\begin{tabular}{|c|c|c|c|c|c|c|c|c|c|c|}
\hline \multirow{2}{*}{ Group } & \multicolumn{2}{|c|}{ TNF- $\alpha(\mathrm{Pg} / \mathrm{ml})$} & \multicolumn{2}{|c|}{ IL-1 $\beta(P g / m l)$} & \multicolumn{2}{|c|}{ IL-17 (Pg/ml) } & \multicolumn{2}{|c|}{ PGE2 $(\mathrm{Pg} / \mathrm{ml})$} & \multicolumn{2}{|c|}{ IL-4 (Pg/ml) } \\
\hline & 9 days & 18 days & 9 days & 18 days & 9 days & 18 days & 9 days & 18 days & 9 days & 18 days \\
\hline Normal control & $31.70 \pm 2.21^{\mathrm{e}}$ & $34.77 \pm 0.64^{\mathrm{e}}$ & $32.70 \pm 0.97^{\mathrm{e}}$ & $37.93 \pm 0.84^{\mathrm{e}}$ & $32.77 \pm 1.33^{\mathrm{d}}$ & $37.27 \pm 1.38^{\mathrm{d}}$ & $127.03 \pm 1.06 \mathrm{e}$ & $126.96 \pm 4.44^{e}$ & $113.96 \pm 7.77^{\mathrm{a}}$ & $116.60 \pm 3.60^{\mathrm{a}}$ \\
\hline Arthiritic control & $118.37 \pm 1.38^{b}$ & $151.90 \pm 11.35^{a}$ & $97.40 \pm 6.16^{b}$ & $126.30 \pm 4.34^{\mathrm{a}}$ & $104.00 \pm 3.42^{b}$ & $170.00 \pm 10.86$ & $257.70 \pm 15.41^{b}$ & $337.27 \pm 10.63^{\mathrm{a}}$ & $56.50 \pm 2.40^{c}$ & $42.36 \pm 2.59^{d}$ \\
\hline $\begin{array}{l}\text { Arthiritic treated } \\
\text { with MTHE }\end{array}$ & $71.17 \pm 2.82^{\mathrm{d}}$ & $86.17 \pm 4.97^{\mathrm{c}}$ & $64.33 \pm 5.38^{d}$ & $78.63 \pm 1.11^{\mathrm{c}}$ & $82.07 \pm 1.32^{c}$ & $90.23 \pm 4.55^{\mathrm{bc}}$ & $178.60 \pm 8.85^{\mathrm{d}}$ & $234.76 \pm 5.60^{b}$ & $89.70 \pm 3.93^{b}$ & $98.23 \pm 1.24^{b}$ \\
\hline $\begin{array}{l}\text { Arthiritic treated } \\
\text { with silymarin }\end{array}$ & $80.4 \pm 2.20^{c}$ & $89.73 \pm 2.43^{c}$ & $66.16 \pm 2.90^{\mathrm{d}}$ & $69.46 \pm 5.29^{\mathrm{cd}}$ & $77.07 \pm 4.32^{c}$ & $81.77 \pm 6.34^{\circ}$ & $190.20 \pm 5.31^{\text {cd }}$ & $208.80 \pm 4.30^{\circ}$ & $88.83 \pm 2.67^{b}$ & $100.57 \pm 4.99^{b}$ \\
\hline LSD at $5 \%$ level & \multicolumn{2}{|c|}{0.706} & \multicolumn{2}{|c|}{0.706} & \multicolumn{2}{|c|}{0.706} & \multicolumn{2}{|c|}{0.706} & \multicolumn{2}{|c|}{0.706} \\
\hline LSD at $1 \%$ level & \multicolumn{2}{|c|}{0.951} & \multicolumn{2}{|c|}{0.951} & \multicolumn{2}{|c|}{0.951} & \multicolumn{2}{|c|}{0.951} & \multicolumn{2}{|c|}{0.951} \\
\hline
\end{tabular}

- Data are expressed as Mean \pm SE. Number of animals in each group is six.

- Within each column, means, which have different superscript letter, are significantly different at $p<0.05$.

Table 4: Effect of MTHE and silymarin on liver SOD, GPx and GST activities, GSH content and LPO in arthritic rats

\begin{tabular}{|c|c|c|c|c|c|c|c|c|c|c|}
\hline \multirow[b]{2}{*}{ Group } & \multicolumn{2}{|c|}{$\begin{array}{c}\text { LPO (nmole MDA/100 gm } \\
\text { tissue/hour) }\end{array}$} & \multicolumn{2}{|c|}{$\begin{array}{c}\text { GSH } \\
\text { (nmol/100 mg tissue) }\end{array}$} & \multicolumn{2}{|c|}{$\begin{array}{c}\text { GPX } \\
(\mathrm{mU} / 100 \mathrm{gm} \text { tissue })\end{array}$} & \multicolumn{2}{|c|}{$\begin{array}{c}\text { GST } \\
(\mathrm{U} / \mathrm{g} \text { tissue })\end{array}$} & \multicolumn{2}{|c|}{$\begin{array}{c}\text { SOD } \\
(\mathrm{U} / \mathrm{g} \text { tissue })\end{array}$} \\
\hline & 9 days & 18 days & 9 days & 18 days & 9 days & 18 days & 9 days & 18 days & 9 days & 18 days \\
\hline Normal control & $31.33 \pm 3.05^{\mathrm{c}}$ & $58.50 \pm 3.44^{c}$ & $35.74 \pm 0.61^{\mathrm{ab}}$ & $40.15 \pm 4.17^{\mathrm{a}}$ & $27.30 \pm 1.38^{c}$ & $27.53 \pm 1.33^{c}$ & $607.67 \pm 31.28^{\mathrm{ab}}$ & $618.33 \pm 18.55^{\mathrm{ab}}$ & $17.32 \pm 0.27^{\mathrm{ab}}$ & $16.80 \pm 0.10^{\mathrm{ab}}$ \\
\hline Arthiritic control & $154.34 \pm 25.80^{\mathrm{a}}$ & $116.05 \pm 11.17^{b}$ & $21.84 \pm 1.97^{d}$ & $21.76 \pm 3.40^{\mathrm{d}}$ & $20.42 \pm 0.58^{\mathrm{d}}$ & $17.22 \pm 0.67^{\mathrm{d}}$ & $485.17 \pm 72.75^{c}$ & $552.67 \pm 47.65^{\text {bc }}$ & $16.80 \pm 0.13^{\mathrm{abc}}$ & $16.70 \pm 0.29^{\mathrm{abc}}$ \\
\hline $\begin{array}{l}\text { Arthiritic treated } \\
\text { with MTHE }\end{array}$ & $65.74 \pm 18.10^{c}$ & $36.60 \pm 3.63^{c}$ & $40.33 \pm 3.80^{\mathrm{a}}$ & $30.61 \pm 0.78^{b c}$ & $31.18 \pm 0.62^{b}$ & $33.77 \pm 2.05^{b}$ & $683.33 \pm 31.2^{\mathrm{a}}$ & $665.83 \pm 43.77^{\mathrm{ab}}$ & $17.40 \pm 0.65^{\mathrm{ab}}$ & $16.50 \pm 0.37^{\mathrm{bc}}$ \\
\hline $\begin{array}{l}\text { Arthiritic treated } \\
\text { with silymarin }\end{array}$ & $100.80 \pm 2.13^{b}$ & $51.82 \pm 3.17^{\mathrm{c}}$ & $28.09 \pm 2.14^{\mathrm{cd}}$ & $25.61 \pm 1.80^{\mathrm{cd}}$ & $37.75 \pm 0.85^{\mathrm{a}}$ & $31.13 \pm 0.67^{b}$ & $551.83 \pm 22.45^{\text {bc }}$ & $607.67 \pm 26.87^{\mathrm{ab}}$ & $17.63 \pm 0.16^{\mathrm{a}}$ & $15.95 \pm 0.33^{c}$ \\
\hline LSD at $5 \%$ level & \multicolumn{2}{|c|}{34.87} & \multicolumn{2}{|c|}{7.64} & \multicolumn{2}{|c|}{3.27} & \multicolumn{2}{|c|}{116.42} & \multicolumn{2}{|c|}{0.952} \\
\hline LSD at $1 \%$ level & \multicolumn{2}{|c|}{46.97} & \multicolumn{2}{|c|}{10.29} & \multicolumn{2}{|c|}{4.40} & \multicolumn{2}{|c|}{156.79} & \multicolumn{2}{|c|}{1.28} \\
\hline
\end{tabular}

- Data are expressed as Mean \pm SE. Number of animals in each group is six.

- Within each column, means, which have different superscript letter, are significantly different at $p<0.05$. 
Microscopical examination of the ankle of normal rats revealed normal histological structure and architecture at 9 days (Figure 1A) and 18 days (Figure 2A). The CFA-induced arthritic rats exhibited an inflammatory cells infiltration, synovial hyperplasia, pannus formation and fibrosis between the articular cartilage after 9 days of CFA injection (Figures 1A, 1B and 1C). As the period extended to 18 days, there were focal necrosis of the articular cartilage and massive inflammatory infiltration of the synovial cavity (Figures $2 \mathrm{~A}$ and $2 \mathrm{~B}$ ). By comparison, the arthritic rats treated with MTHE revealed an obvious reduction in inflammation and joint destruction. Some animals exhibited joint histology almost identical to that of normal rats (Figure 1E) and others showed pannus formation (Figure $1 \mathrm{~F}$ ) and few inflammatory cells infiltration (Figure 1G) after 9 days. After 18 days of MTHE administration, some animals exhibited normal joint architecture (Figure 2D) and others showed pannus formation and few inflammatory cells infiltration (Figures $2 \mathrm{~F}$ and $2 \mathrm{E})$. On the other hand, the treatment of arthritic rats with silymarin produced a marked improvement of the histopathological changes. The joint histology of some animals was almost identical with that of normal rats after 9 days (Figures $1 \mathrm{H}$ and Figure 1I) and others showed focal degeneration of cartilage (Figure 1J). After 18 days of CFA injection, some animals showed degeneration of chondrocytes (Figure 2G) and others showed improved histological section to near normal histological appearance (Figures $2 \mathrm{H}$ and $\mathrm{HI}$ ).

H\&E-stained sections of control group spleens exhibited normal histological structure of the lymphoid cells in the white and red pulps after 9 and 18 days (Figures $3 \mathrm{~A}$ and $4 \mathrm{~A}$ ). The spleen sections of arthritic control animals showed lymphoblastic activation, lymphocytic necrosis and mitotic (Figures 3B, 3C and 3D) after 9 days of CFA injection. After 18 days of injection by CFA, spleen of arthritic rats exhibited lymphocytic necrosis, lymphoblastic activation, and mitotic (Figures 4B, 4C and 4D). Spleen of arthritic rats treated with MTHE after 9 days showed no histopathological changes (Figures $3 \mathrm{E}$ and $3 \mathrm{~F}$ ) with some animals, while others exhibited mitotic figure appearance (Figure $3 \mathrm{G}$ ). As the period was prolonged to 18 days, some animals exhibited mitotic figure appearance (Figures $4 \mathrm{E}$ and $4 \mathrm{G}$ ) and others exhibited normal lymphoid follicle (Figure 4F). On the other hand, spleen of arthritic rats treated with silymarin exhibited a mitotic figure for some animals (Figure $3 \mathrm{H}$ ) and no histological changes for other animals and improved histopathological alterations after 9 days (Figure 3I) and after 18 days, spleen sections exhibited no histopathological changes (Figure 4H).

The examination of H\&E-stained sections of control rat thymus after 9 and 18 days, shown in Figures 5 and 6, respectively. The thymus of normal rats exhibited normal histological structure of the lymphoid cells in both cortex and medulla and normal thymic lobules (Figures 5A and 6A). The thymus of the arthritic control rats exhibited mitotic figure view after 9 days of CFA injection (Figures 5B and 5C). After 18 days of CFA injection, the thymus of arthritic control rats also exhibited mitotic figure (Figure 6B) and lymphoblasts activation (Figure 6C). The thymus of arthritic rats treated with MTHE after 9 days exhibited no histopathological changes and normal appearance after 9 days (Figures 5D, 5E and $5 \mathrm{~F}$ ) and 18 days (Figures $6 \mathrm{D}$ and $6 \mathrm{E}$ ). After 9 days of treatment with silymarin, thymus of some animals showed no histopathological changes (Figure 5G), while others exhibited slight lymphocytic necrosis (Figure $5 \mathrm{H}$ ). As the period extended to 18 days, thymus of arthritic rats treated with silymarin showed no histopathological changes (Figures 6F and 6G).

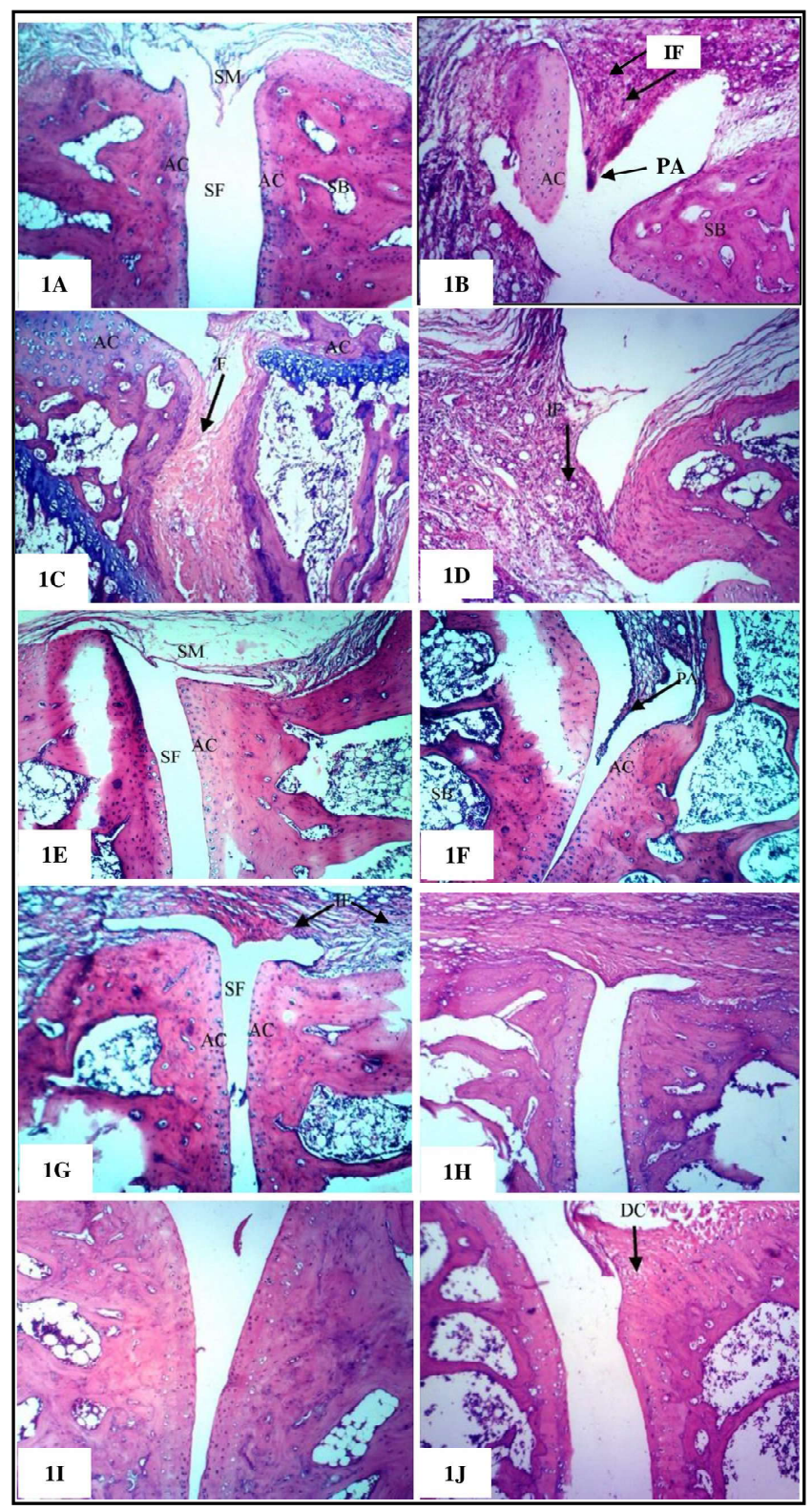

Figure 1: Photomicrographs of ankle joints sections of normal rats (1A), arthritic rats (1B, 1C and $1 \mathrm{D})$ and arthritic rats treated with MTHE (1E, $1 \mathrm{~F}$ and $1 \mathrm{G})$ and silymarin $(1 \mathrm{H}, 1 \mathrm{I}$ and $1 \mathrm{~J})$ at the 9th day. 1A depicted normal histological structure of ankle joint. SF, AC, SB and SM respectively refer to synovial fluid, articulating cartilage, sponge bone and synovial membrane. 1B, 1C and 1D showed massive inflammatory cells infiltration (IF), pannus formation (PA), fibrosis (F) between the articular cartilage. $1 \mathrm{E}, 1 \mathrm{~F}$ and $1 \mathrm{G}$ showed nearly normal histological architecture, mild pannus formation (PA) and few inflammatory cells infiltration (IF) respectively. 1H, 1I and $1 \mathrm{~J}$ showed no histopathological changes and mild focal degeneration of articular cartilage (DC). (H\&E X 100). 


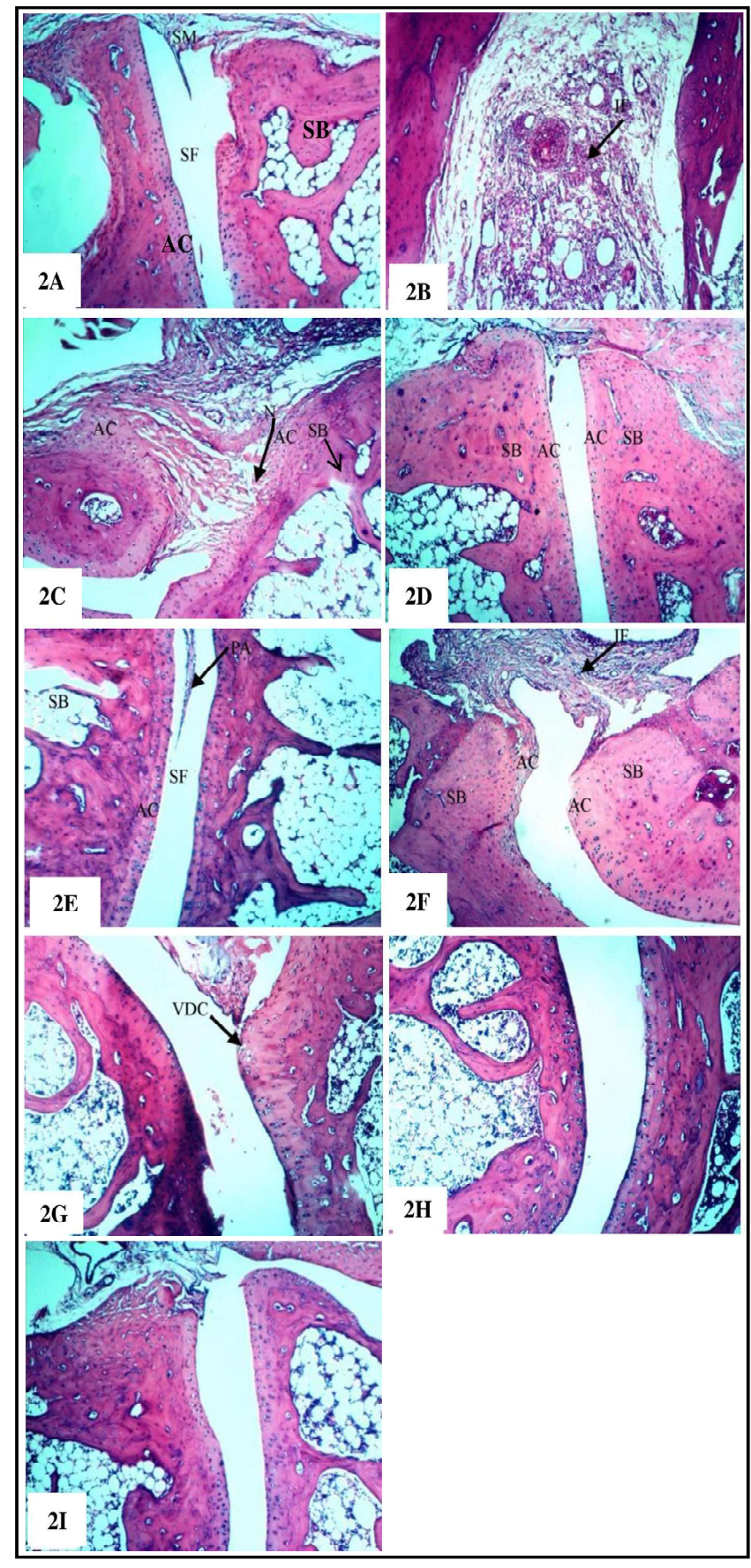

Figure 2: Photomicrographs of ankle joints sections of normal rats (2A), arthritic rats $(2 \mathrm{~B}$ and $2 \mathrm{C})$ and arthritic rats treated with MTHE $(2 \mathrm{D}, 2 \mathrm{E}$ and $2 \mathrm{~F})$ and silymarin $(2 \mathrm{G}, 2 \mathrm{H}$ and $2 \mathrm{I})$ at the 18 th day. 2A depicted normal histological structure of ankle joint. SF, $\mathrm{AC}, \mathrm{SB}$ and SM respectively refer to synovial fluid, articulating cartilage, sponge bone and synovial membrane. $2 \mathrm{~B}$ and $2 \mathrm{C}$ showed focal necrosis of cartilage $(\mathrm{N})$ and massive inflammatory cells infiltration (IF). 2D, 2E and $2 \mathrm{~F}$ respectively showed no histopathological changes, pannus formation (PA) and few inflammatory cells infiltration (IF). 2G depicted mild vacuolar degeneration of chondrocyte (VDC) while $2 \mathrm{H}$ and $2 \mathrm{I}$ showed no histopathological changes (H\&E X 400).

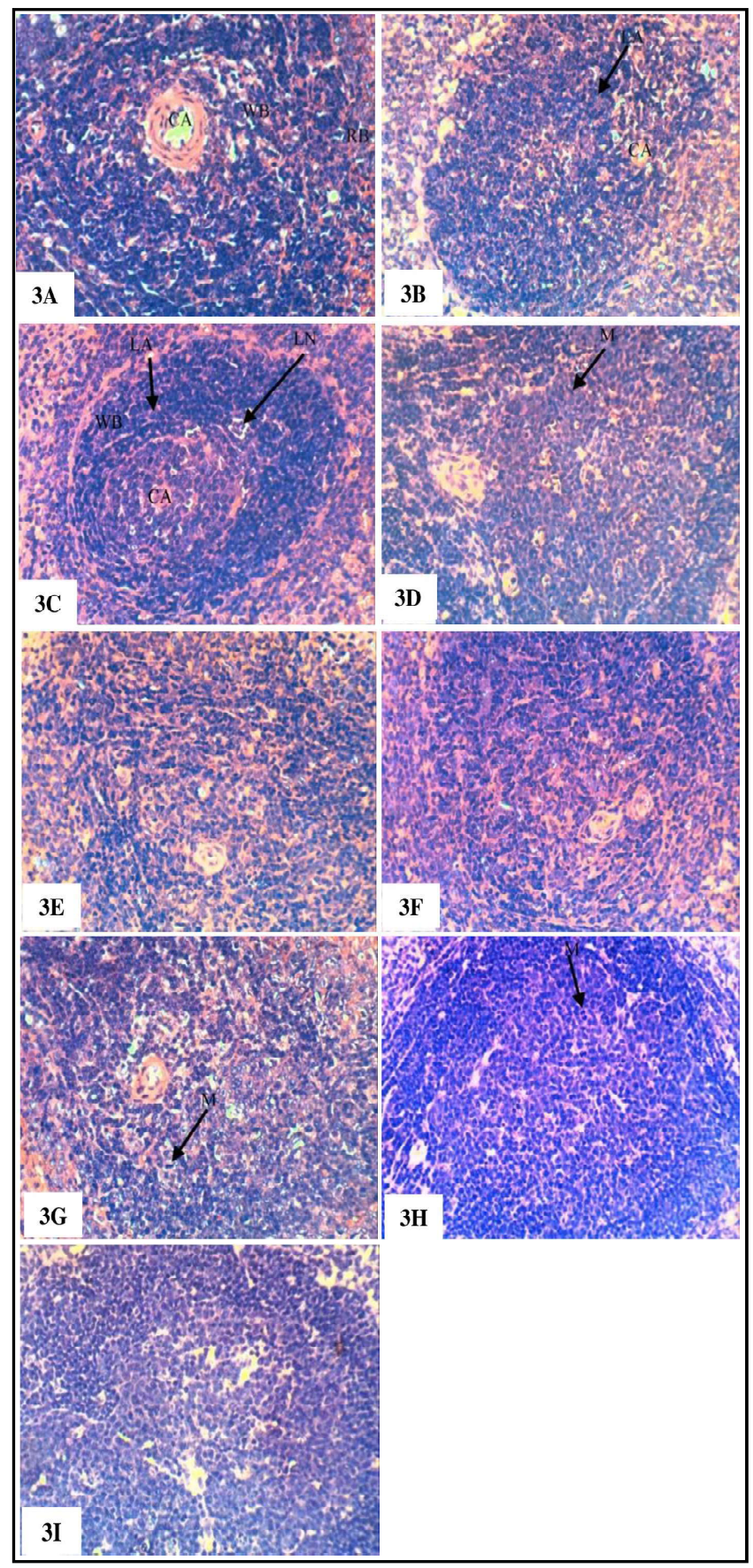

Figure 3: Photomicrographs of spleen sections of normal group (3A), arthritic group (3B, 3C and $3 \mathrm{D}$ ), arthritic group treated with MTHE (3E, 3F and 3G) and arthritic group treated with silymarin (3H and 3I) after 9 days. 3A showed normal red (RB) and white (WB) pulp and central artery (CA). 3B, 3C and $3 \mathrm{D}$ depicted lymphoblasts activation (LA), slight lymphocytic necrosis (LN) and mitotic (M) figure. $3 \mathrm{E}$ and $3 \mathrm{~F}$ depicted no histopathological changes. $3 \mathrm{G}$ and $3 \mathrm{H}$ depicted mitotic (M) figure. 3I showed no histopathological changes. (H\&E X 400). 


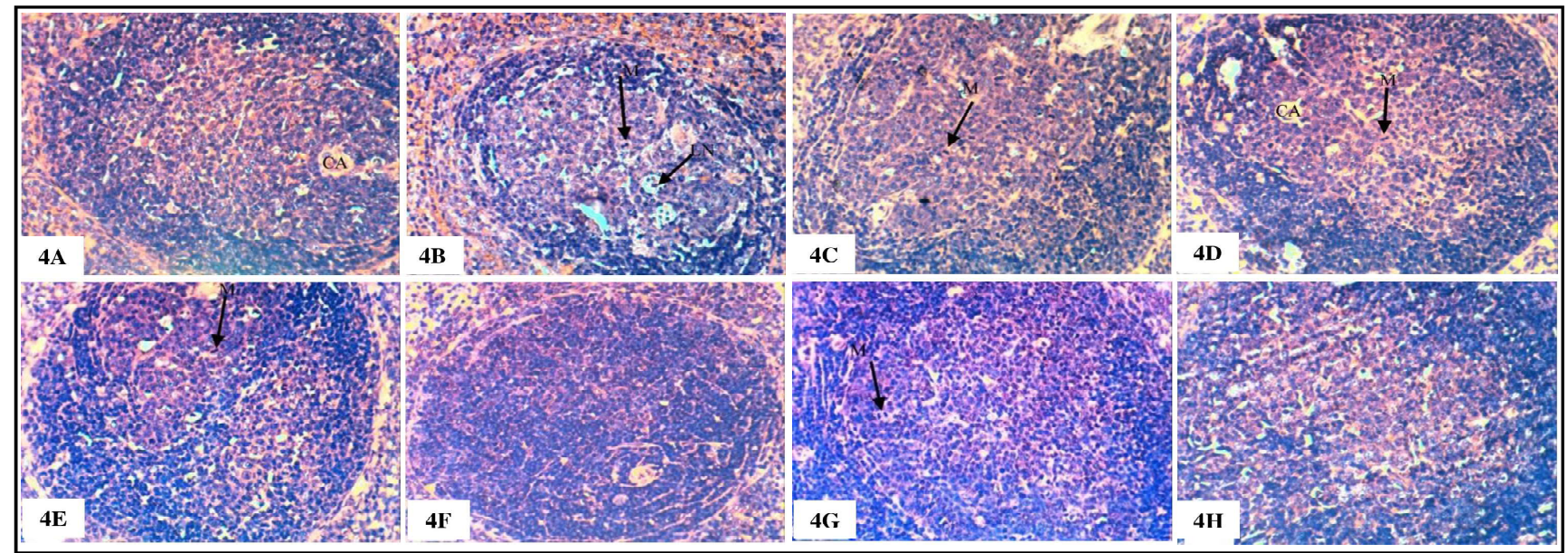

Figure 4: Photomicrographs of spleen sections of normal group (4A), arthritic group (4B, 4C and 4D), arthritic group treated with MTHE (4E, 4F and 4G) and arthritic group treated with silymarin (4H) after 18 days. 4A showed normal red pulp (RB) and white pulp (WB). 4B, 4C and 4D showed lymphocytic necrosis (LN) associated with mitotic figure (M). 2B and 2C showed mitotic (M) figure. The symbol CA refers to central artery. 4E and 4G depicted mitotic (M) figures. 4F showed no histopathological changes with normal lymphoid follicle. (H\&E X 400).

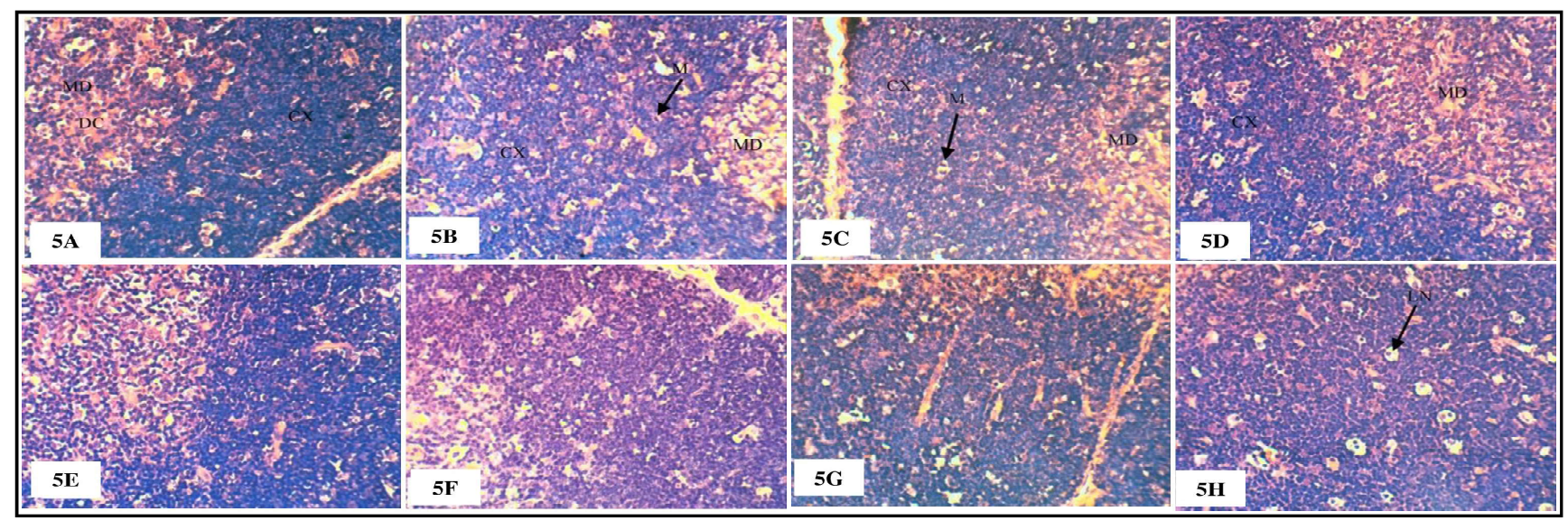

Figure 5: Photomicrographs of thymus section of normal group (5A), arthritic group (5B and 5C), arthritic group treated with $\mathrm{MTHE}$ (5D, 5E and 5F) and arthritic group treated with silymarin $(5 \mathrm{G}$ and $5 \mathrm{H})$ after 9 days. $5 \mathrm{~A}$ showed no histopathological changes with normal thymic lobule. $\mathrm{CX}$, $\mathrm{MD}$ and $\mathrm{DC}$ respectively refer to cortex, medulla and dendritic cell. 5B and 5C showed mitotic (M) figure. The symbols CX and $\mathrm{MD}$ respectively refer to cortex and medulla. $5 \mathrm{D}, 5 \mathrm{E}$ and $5 \mathrm{~F}$ showed no histopathological changes. $\mathrm{CX}$ and $\mathrm{MD}$ respectively refer to cortex and medulla 5G and 5H respectively showed no histopathological changes and slight lymphocytic necrosis (LN) (H\&E X 400).

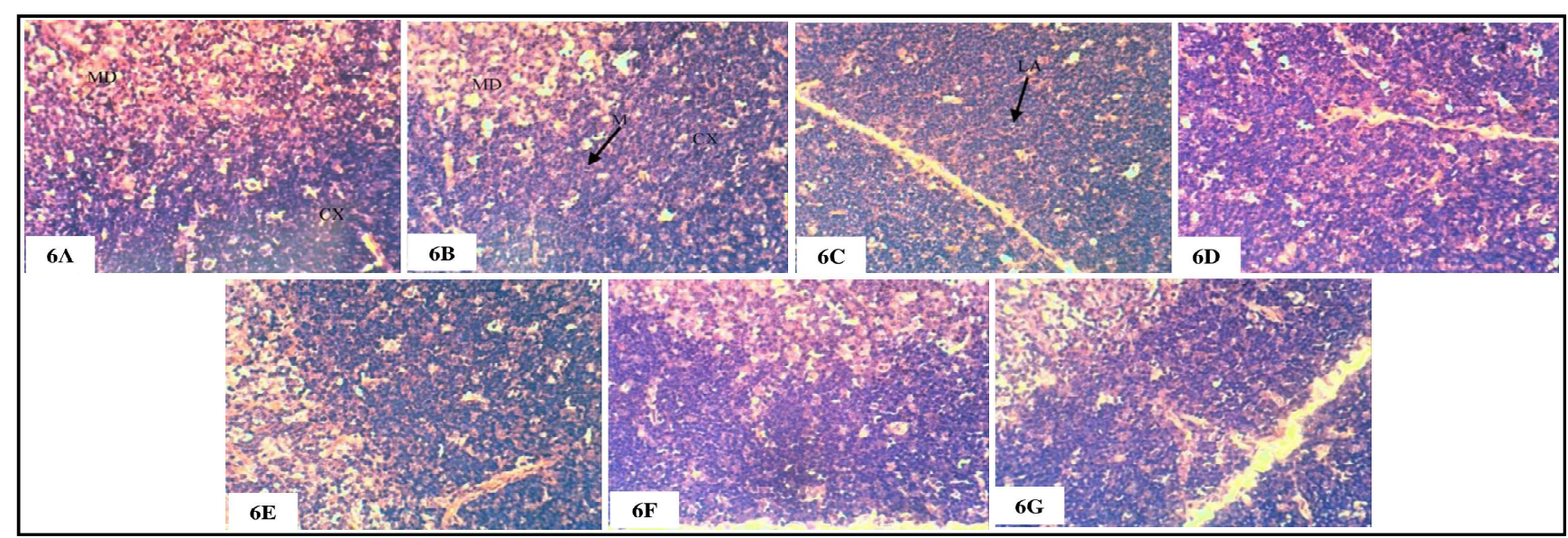

Figure 6: Photomicrographs of thymus section of normal group (6A), arthritic group (6B and 6C), arthritic group treated with MTHE (6D and 6E) and arthritic group treated with silymarin $(6 \mathrm{~F}$ and $6 \mathrm{G}$ ) after 18 days. $6 \mathrm{~A}$ showed no histopathological changes with normal thymic lobule. CX, MD respectively refer to cortex, medulla $6 \mathrm{~B}$ and $6 \mathrm{C}$ respectively showed mitotic figure $(\mathrm{M})$ and lymphoblasts activation (LA). The symbols CX and $\mathrm{MD}$ respectively refer to cortex and medulla. $6 \mathrm{D}, 6 \mathrm{E}, 6 \mathrm{~F}$ and $6 \mathrm{G}$ showed no histopathological changes. (H\&E X 400). 


\section{Discussion}

CFA-induced arthritis is one of the best animal models of chronic polyarthritis with features similar to human RA and it involves cell mediated autoimmunity (Gohil et al., 2018). Therefore, inhibition of CFA model is widely used to investigate antiarthritic agents. Because of the wide range of the reported pharmacological activities of MTHE and silymarin including anti-inflammatory and antioxidant actions, their effects were assessed in CFA-induced arthritic rats in the present study.

Changes within rheumatoid indices like RHPC, paw thickness and paw volume has been used to assess the anti-inflammatory effects upon RA (Chen et al., 2017).

The rats injected with CFA exhibited a significant increase in ankle joint circumference after 9 and 18 days and this is in accordance with Ahmed et al. (2018b). The ankle joint circumference increase suggests the swelling rate due to odema and hyperplasia in the synovium which were caused by massive inflammatory infiltrate which are proved by histological observation of the present study. As illustrated in the histological results, the arthritic ankle joint exhibited fibrosis between the articular cartilage, pannus formation, focal necrosis of the cartilage and appearance of inflammatory cells infiltration after 9 and 18 days of CFA injection. Treatment of arthritic rats with MTHE exhibited a significant decrease of the RHPC after 9 days only. The decrease in ankle joint circumference as a result of MTHE was associated with appearance of few inflammatory cells infiltration, decrease in the swelling rate which may be attributed to a decrease in odema and reduction in the inflammatory process after 9 and 18 days and these changes were evidenced by the current histopathological results. On the other hand, the treatment with silymarin induced a significant decrease of the ankle joint circumference after 9 and 18 days. Treatment with silymarin appeared to be more potent after 18 days and these results were evidenced by histopathological studies.

RF (a circulating antibody toward immunoglobulin $\mathrm{G}$ ) is an important serum marker in the RA diagnosis and it is used to assist in the RAseverity prognosis (Chandrashekara et al., 2002).

In the present study, serum RF level has been, significantly, elevated in CFA-induced arthritic rats after 9 and 18 days which in agreement with (Zhu et al., 2020). The elevation in RF in association with the increase in RHPC after 9 and 18 days of CFA injection reflects the right hind ankle joint swelling, edema, and inflammation and thereby arthritis.

The treatment of arthritic rats with MTHE and silymarin induced a profound improvement of the elevated RF level after 9 and 18 days. The decrease in the RHPC and RF level reflect the antiarthritic efficacies of both treatments indicating the anti-inflammatory activities of MTHE or silymarin.

The TLC of arthritic control rats showed significant leukocytosis after 9 and 18 days of adjuvant injection; this leukocytosis is considered to be an implication of inflammatory systemic reaction in the body (Kumar et al., 2004). Leukocytosis, in the present study, is linked to inflammation triggered by CFA which is an antigen of weakened or killed Mycobacterium tuberculosis emulsified in mannide mono-oleate and mineral oil (Stils, 2005). The treatment of arthritic rats with MTHE markedly decreased the elevated TLC after 9 and 18 days; the effect was significant and more potent after 9 days of CFA injection. The treatment of arthritic rats with silymarin, on the other hand, induced a significant decrease of the TLC at both tested periods.

The DLC data in arthritic control rats showed significant increase in neutrophil, lymphocyte, monocyte, and eosinophil counts after 9 and 18 days of CFA injection which is concomitant with Neves et al. (2020). Arthritic rats treated with MTHE and silymarin induced a significant decrease in neutrophil, lymphocyte, monocyte, and a non-significant effect on eosinophil count after 9 and 18 days as compared with the corresponding arthritic control.

The TLC and DLC findings, in the present study, are concomitant with the histological results which revealed massive inflammatory cells in the joint capsule, lymphoblasts activation in the white pulp of spleen and infiltration of mononuclear cells in the thymus of arthritic rats. A suggested mechanism explaining the antiinflammatory effect of silymarin was introduced though its inhibitory effects on neutrophil degranulation and MPO activity (Zholobenko et al., 2016).

RA is an inflammatory disease characterized by the predominance of Th1 over Th2, thereby the overexpression of pro-inflammatory as well as inflammatory cytokines. To investigate the possible anti-inflammatory mechanisms of action of MTHE and its active constituent silymarin, concentrations of pro-inflammatory cytokines (TNF- $\alpha$, IL-1 $\beta$ and IL-17), PGE2 (acute inflammatory cytokine) and the anti-inflammatory cytokine (IL-4) were determined in the sera of rats.

TNF- $\alpha$ and IL- $1 \beta$ are suggested to play a key role in RA pathogenesis due to their increased levels within synovial fluid, synovial tissue and plasma of patients with RA. TNF- $\alpha$ and IL- $1 \beta$ exhibit, particularly, a critical role by causing the release of PGE2 and metalloproteases (stromelysin and collagenases) by stimulated cells (synovial dendritic cells, macrophages, fibroblasts) (Hamdi et al., 2006). This causes bone resorption, cartilage destruction, and synoviocytes chronic proliferation (Sibilia and Sordet, 2005).

IL-17 acts synergistically with TNF- $\alpha$ and IL- $1 \beta$ to promote catabolism of cartilage (Dudler et al., 2000). IL-17 has been associated with recruitment of tissue neutrophil though stimulation of granulocyte colony-stimulating factor and IL-8 (Kolls and Linden, 2004). Moreover, PGE2 exhibit an inflammatory role; it can stimulate IL-23 production from dendritic cells (DCs), which promote pro-inflammatory Th17 cells differentiation (Khayrullina et al., 2008). On the other hand, IL-4 improves monocyte apoptosis, thus decreases accumulation of monocyte (Mangan et al., 1992).

The data of present study also indicated that serum TNF- $\alpha$, IL-1 $\beta$ and PGE2 levels significantly elevated after 9 and 18 days of CFA injection. These results go parallel with histology outcome as well as hind leg joints swelling.

The serum level of other pro-inflammatory cytokine, IL-17, significantly elevated after 9 and 18 days following CFA injection while serum level of Th2, IL-4, significantly decreased after the same periods. This evidence is in agreement with Ahmed et al. (2018 c). 
The treatment of arthritic rats with MTHE and silymarin resulted in a significant decrease in levels of TNF- $\alpha$, IL-1 $1 \beta$, IL-17 and PGE2 as well as a significant increase in IL-4; the treatment with silymarin appeared to be more potent than MTHE in decreasing PGE2 after 18 days. These results reflect the anti-inflammatory properties of MTHE and silymarin. It was suggested that silymarin perform anti inflammatory actions and attenuates immune mediated and autoimmune liver diseases, by suppression of oxidative and nitrosative immunotoxicity as well as Tlymphocyte function (Mili et al., 2013).

The cytokine data are supported by the histopathological observation of sections of the ankle joint. The treatment with MTHE and silymarin induced few inflammatory cells infiltration and normal architecture of the joint of others after 9 and 18 days of adjuvant injection when compared with the arthritic control group. This clearly indicates the improvement in the histopathological impacts and suppression of inflammatory cells infiltration in joints by the two treatments.

Oxidative stress plays an important role in the pathogenesis of rheumatoid arthritis (Fonseca et al., 2019). CFA-induced arthritis is linked to mono and poly-morphonuclear cells (PMN) accumulation in the joint. Stimulation of these cells results in free radicals' generation that causes damage in the joint structure (Umar et al., 2012). Antioxidants like GSH, GPx, GST and SOD are very important mechanisms protecting the cell from free radicals (Bhattacharyya et al., 2014).

Hepatic involvement in RA is associated with an abnormal liver function analysis, a little inflammatory chronic infiltrate within the portal tract, fatty liver, and small necrotic foci (Abraham et al., 2004). The liver has the highest metabolic activity and it is considered as the energy house of the body; thereby it produces excessive amount of ROS and free radicals. These free radicals can be released to blood and may affect other organs and ankle joints.

In the present study, LPO level significantly elevated in CFA-induced arthritic rats as compared to normal and significantly reduced by treatments of arthritic rats with MTHE and silymarin due to their antioxidant properties. The antioxidant activities of MTHE and silymarin were evidenced by their efficiencies to increase the lowered GSH content and GPx and GST activities in arthritic rats as evidenced in the results of the present study. MTHE was more effective in decreasing LPO level and in increasing GSH content and GST activity than silymarin. In our opinion, more potent effect of MTHE may be due to presence of other antioxidant constituents in addition to silymarin.

GSH contribute in free radicals' removal such as alkoxy radical, $\mathrm{H}_{2} \mathrm{O}_{2}$ and superoxide anions, maintaining thiols of membrane proteins and also as a substrate for GSH reductase and GPx (Naik et al., 2011). In the present study, a marked drop in hepatic GSH content was noticed in arthritic control group after 9 and 18 days. The treatments of CFA-induced arthritic rats with MTHE and silymarin resulted in a significant increase in liver content of GSH which is substrate for GSH reductase (GR), GPx and GST enzymes.

In the present study, GPx and GST activities in arthritic rats showed a significant reduction, however the treatment with MTHE for
9 days produced a significant enhancement of GST activity in arthritic rats. On the other hand, SOD activity showed no change by any of the tested compounds.

Silymarin is a well extracted milk thistle seeds dry standardized extract including mainly flavonolignans as well as oxidized and polymeric polyphenolic compounds containing a mixture of flavonoids (Abenavoli et al., 2018). This composition may be responsible for antioxidant and anti-inflammatory properties of milk thistle and silymarin. Additionally, silibinin, the major active constituent of silymarin, was proofed to have immunosuppressive role during treating rheumatoid arthritis patients, in both males and females (Dupuis et al., 2018; Shavandi et al., 2017).

The spleen which is a lymphoid organ has an important role in immune responses toward any antigen appear in the blood. Considering the spleen sections of normal rats, it exhibited normal histological structure of the lymphoid cells in the white and red pulps. The CFA-induced arthritic control group showed lymphoblast' activation, mitotic figure, and slight lymphocytic necrosis after 9 and 18 days in the white pulps.

The treatment of the arthritic rats with MTHE and silymarin produced a mitotic figure appearance in some animals and normal architecture of the spleen in others. This indicates that the two treatments may be useful agents in improving the histopathological alterations in spleen sections of CFA-induced arthritic rats.

Similarly to the spleen, the thymus of normal rats exhibited a normal histological structure of the lymphoid cells in both cortex and medulla. Thymus sections from arthritic control rats showed a mitotic figure appearance and lymphoblastic proliferation after 9 and 18 days of CFA injection. Treatment with MTHE exhibited a remarkable improvement in the histopathological changes (normal structure of lymphoid cells in cortex and medulla) after 9 and 18 days. On the other hand, the treatment with silymarin exhibited lymphocytic necrosis after 9 days and normal architecture of thymus after 18 days. This indicates that the two treatments may be powerful agents in improving the histopathological deteriorations in thymus sections of CFA-induced arthritic rats.

\section{Conclusion}

Both of MTHE and silymarin have anti-arthritic potentials which may be mediated via their anti-inflammatory and antioxidant effects in CFA-induced arthritic rats. However, further clinical studies are recommended to assess the efficacy of MTHE and silymarin in human beings with rheumatoid arthritis.

\section{Funding}

This research did not receive any specific grant from funding agencies in the public, commercial, or not-for-profit sectors.

\section{Experimental animal ethics}

All animal procedures are in accordance with the guidelines of Experimental Animal Ethics Committee, Faculty of Science, BeniSuef University, Beni-Suef, Egypt (Ethical Approval Number: BSU/ FS/ 2017/22). All efforts were done to reduce the number and pain of animals. 


\section{Acknowledgments}

The authors thank Prof. Dr. Kawkab A. Ahmed, Professor of Histopathology, Pathology Department, Faculty of Veterinary Medicine, Cairo University, Egypt and Prof. Dr. Rasha R. Ahmed, Professor of Molecular Cell Biology, Cell Biology, Histology and Genetics Division, Zoology Department, Faculty of Science, BeniSuef University, Beni-Suef, Egypt for help in examining and determining the lesions in the ankle, spleen and thymus histological stained sections.

\section{Conflict of interest}

The authors declare that there are no conflicts of interest in the course of conducting the research. All the authors had final decision regarding the manuscript and decision to submit the findings for publication.

\section{Abbreviations used}

AIA, adjuvant induced arthritis; CFA, Complete Freund's Adjuvant; CIA, collagen type II-induced arthritis; CD, cluster differentiation; DLC, differential leucocyte count; DCs, dendritic cells; GSH, reduced form of glutathione; GPx, glutathione peroxidase; GST, glutathione-S transferase; IFN, interferon; IL, interleukin; LPO, lipid peroxidation; MDA, malondialdehyde; MTHE, milk thistle seeds hydroethanolic extract; PGE2, prostaglandin E2; RA, rheumatoid arthritis; RF, Rheumatoid factor; RHPC, right hind paw circumference; ROS, reactive oxygen species; SOD, superoxide dismutase; Th, Thelper; TLC, total leucocyte count; TNF- $\alpha$, tumor necrosis factor alpha.

\section{References}

Abdel Aziz, S.M.; Ahmed, O.M.; Abd El-Twab, S.M.; Al-Muzafar, H.M.; Amin, K.A. and Abdel-Gabbar, M. (2020). Antihyperglycemic effects and mode of actions of Musa paradisiaca leaf and fruit peel hydroethanolic extracts in nicotinamide/streptozotocin-induced diabetic rats. Evid Based Complement Alternat Med., 2020:9276343. doi:10.1155/ 2020/9276343

Abenavoli, L.; Izzo, A.A.; Milić, N.; Cica'la, C.; Santini, A. and Capasso, R. (2018). Milk thistle (Silybum marianum). A concise overview on its chemistry, pharmacological, and nutraceutical uses in liver diseases. Phytother Res,. 32(11):2202-2213.

Abraham, S.; Begum, S. and Isenberg, D. (2004). Hepatic manifestations of autoimmune rheumatic diseases. Ann. Rheum. Dis., 63(2):123-129.

Ahmed, O.; Fahim, H.; Mahmoud A. and Ahmed, E.A.E. (2018a). Bee venom and hesperidin effectively mitigate complete Freund's adjuvantinduced arthritis via immunomodulation and enhancement of antioxidant defense system. Arch Rheumatol., 33(2):198-212.

Ahmed, O.M.; Ashour, M.B.; Fahim, H.I. and Ahmed, N.A. (2018b). Citrus limon and paradisi fruit peel hydro-ethanolic extracts prevent the progress of complete Freund's adjuvant-induced arthritis in male wistar rats. Adv. Anim. Vet. Sci., 6(10):443-455.

Ahmed, O.M.; Ashour, M.B.; Fahim, H.I. and Ahmed, N.A. (2018c). The role of Th1/Th2/Th17 cytokines and antioxidant defense system in mediating the effects of lemon and grapefruit peel hydro-ethanolic extracts on adjuvant-induced arthritis in rats. J. Appl. Pharm. Sci., 8(10):069-081.

Ahmed, O.M.; El-Abd, S.F.; El Mahdi, E.A. and Abdou, E.A. (2015). Curcumin ameliorative efficacy on type 1 diabetes mellitus coexisted with rheumatoid arthritis in Wistar rats. Merit Res. J. Med. Sci., 3(7):256-270.
Ahmed, O.M.; Soliman, H.A.; Mahmoud, B. and Gheryany, R.R. (2017). Ulva lactuca hydro-ethanolic extract suppresses experimental arthritis via its anti-inflammatory and antioxidant activities. Beni-Suef Univ. J. Basic. Appl. Sci., 6(4):394-408.

Ahmed, O.M., Mahmoud, A.M., Zid, S.F., and Saber, N.Y. (2016). Silymarin and hydroethanolic extracts of Silybum marianum leaves and fruits attenuate diethylnitrosamine/phenobarbital-induced nephrotoxicity via their antioxidant and anti-inflammatory actions. American J. Biochem., 6(2):21-29.

Ali, A.M.; Gabbar, M.A. and Abdel-Twab, S.M. (2020). Antidiabetic potency, antioxidant effects, and mode of actions of Citrus reticulata fruit peel hydroethanolic extract, hesperidin, and quercetin in nicotinamide/ streptozotocin-induced wistar diabetic rats. Oxid. Med. Cell Longev., 2020:1730492. doi:10.1155/2020/1730492.

Banchroft, J.D.; Stevens, A. and Turner, D.R. (1996). Theory and practice of histological techniques. $4^{\text {th }}$ Ed. Churchil living stone. New York, London, San Francisco, Tokyo. pp:76.

Bhattacharyya, A.; Chattopadhyay, R.; Mitra, S. and Crowe, S.E. (2014). Oxidative stress. An essential factor in the pathogenesis of gastrointestinal mucosal diseases. Physiol. Rev., 94(2):329-354.

Bolon, B.; Stolina, M.; King, C.; Middleton, S.; Gasser, J.; Zack, D. and Feige, U. (2011). Rodent preclinical models for developing novel antiarthritic molecules. Comparative biology and preferred methods for evaluating efficacy. Biomed. Res. Int., 2011(569068):21. https://doi.org/10.1155/ $2011 / 569068$

Carmona, L.; Cross, M.; Williams, B.; Lassere, M. and March, L. (2010). Rheumatoid arthritis. Best Pract. Res. Clin. Rheumatol., 24(6): $733-745$.

Chandrashekara, S.; Anilkumar, T. and Jamuna, S. (2002). Complementary and alternative drug therapy in arthritis. J. Assoc. Physicians India, 50:225-227.

Chen, Y.; Wang, Q.W.; Zuo, J.; Chen, J.W. and Li, X. (2017). Anti-arthritic activity of ethanol extract of Claoxylon indicum on Freund's complete adjuvant-induced arthritis in mice. BMC Complement Altern. Med., 17(1):11-17.

Curtis, J.R. and Singh, J.A. (2011). Use of biologics in rheumatoid arthritis: Current and emerging paradigms of care. Clin. Ther., 33(6):679-707.

Das, K.; Khan, M. S.; Namratha, N.; Swetha, R. and Gezici, S. (2019). Comparative phytochemical screening, elemental content and chromatographic evaluation for detection and quantification of polyphenolic compounds for strong antioxidant activity of various extracts of Abutilon indicum (Link) Sweet leaves. Ann. Phytomed., 8(1):36-44.

Dayer, J.M. and Fenner, H. (1992). The role of cytokines and their inhibitors in arthritis. Baillieres Clin. Rheumatol., 6:485-516.

Dudler, J.; Renggli Zulliger, N.; Busso, N.; Lotz, M. and So, A. (2000). Effect of interleukin 17 on proteoglycan degradation in murine knee joints. Ann. Rheum. Dis., 59:529-532.

Dupuis, M.L.; Conti, F. and Maselli, A. (2018). The natural agonist of estrogen receptor $\beta$ silibinin plays an immunosuppressive role representing a potential therapeutic tool in rheumatoid arthritis. Front Immunol., 9:1903. doi: 10.3389/fimmu.2018.01903.

El Mgeed, A.A.; Bstawi, M.; Mohamed, U. and Gabbar, M.A. (2009). Histopathological and biochemical effects of green tea and/or licorice aqueous extracts on thyroid functions in male albino rats intoxicated with dimethylnitrosamine. Nutr. Metab., (Lond). 6:2. doi: $10.1186 / 1743-7075-6-2$ 
Esmaeil, N.; Anaraki, S.B; Gharagozloo, M. and Moayedi, B. (2017). Silymarin impacts on immune system as an immunomodulator: One key for many locks. Int. Immunopharmacol., 50:194-201. doi: 10.1016/ j.intimp.2017.06.030

Fonseca, L.J.A.S.; Nunes-Souza, V.; Goulart, M.O.F. and Rabelo, L.A. (2019). Oxidative stress in rheumatoid arthritis: What the future might hold regarding novel biomarkers and add-on therapies. Oxid. Med. Cellu. Longev., 2019(7536805):16 pages.

Gallagher, A.; Hewitt, G. and Gibson, I. (1972). Differential giemsa staining of heterochromatic B-chromosomes in Myrmeleotettix maculatus (thunb.) (orthoptera: Acrididae). Chromosoma., 40(2):167-172.

Ganesan, R. and Rasool, M. (2019). Ferulic acid inhibits interleukin 17 dependent expression of nodal pathogenic mediators in fibroblas like synoviocytes of rheumatoid arthritis. J. Cell Biochem., 120(2): 1878-1893.

Gohil, P.; Patel, V.; Deshpande, S.; Chorawala, M. and Shah, G. (2018). Antiarthritic activity of cell wall content of Lactobacillus plantarum in Freund's adjuvant-induced arthritic rats: Involvement of cellular inflammatory mediators and other biomarkers. Inflammopharmacol., 26(1):171-181.

Hamdi, H.; Mariette, X. and Godot, V. (2006). The RATIO (Recherche sur anti-TNF et infections opportunistes) study group. Inhibition of antituberculosis T-lymphocyte function with tumour necrosis factor antagonists. Arthritis Res. Ther., 8(4):R114.

Hashem, A.S.; Taha, N.M. and Mandour, A.E.A. (2016). Hepatoprotective Effect of silymarin and propolis in chemically: Induced chronic liver injury in rats. Alex J. Vet. Sci., 49(1):35-43.

Hikal, A.H. and El-Fattah H.M.A. (2018). Comparative study of marjoram (Origanum Majorana L.) and silymarin (Silibum M£inum L.) extract against cabon tetrachloride induced hepatic injury. World J. Pharm. Pharm. Sci., 7(8):1369-1392.

Ionut, M.; Marina, S.; Emoke, P.; Florinel, B.; Monica, S. and Constantin V. (2018) Target cell type dependent immune activity of plant extracts in bovine raised under different technologies. Ann. Phytomed., 7(2): $81-84$.

Karimi, G.; Vahabzadeh, M.; Lari, P.; Rashedinia, M. and Moshiri, M. (2011) "Silymarin", a promising pharmacological agent for treatment of diseases. Iran J. Basic Med. Sci., 14(4):308-317.

Khayrullina, T.; Yen, J.H.; Jing, H. and Ganea, D. (2008). In vitro differentiation of dendritic cells in the presence of prostaglandin E2 alters the IL-12/IL-23 balance and promotes differentiation of Th17 cells. J. Immunol., 181:721-735.

Kolls, J.K. and Linden, A. (2004). Interleukin-17 family members and inflammation. Immunity., 21:467-476.

Kumar, V.; Abbas, A.K. and Fausto Robbins, N. (2004). Cotran Pathologic Basis of Disease. 7 th ed. Saunders, Philadelphia.

Luckheeram, R.; Zhou, R.; Verma, A. and Xia, B. (2012). $\mathrm{CD}^{+} \mathrm{T}$ Cells Differentiation and Functions. Clin. Dev. Immunol., 2012:1-12.

Mangan, D.F.; Robertson, B. and Wahl, S.M. (1992). IL-4 enhances programmed cell death (apoptosis) in stimulated human monocytes. J. Immunol., 148:1812-1816.
Miale, J.B. (1972). Laboratory medicine: Haematology. $4^{\text {th }}$ edition. Saint Lucis: The C.V. Mobsy Co.

Milić, N.; Milosević, N. and Suvajdzić, L. (2013). New therapeutic potentials of milk thistle (Silybum marianum). Nat. Prodt. Commun., 8: $1801-1810$

Naik, S.R.; Thakare, V.N. and Patil, S.R. (2011). Protective effect of curcumin on experimentally induced inflammation, hepatotoxicity and cardiotoxicity in rats: Evidence of its antioxidant property. Exp. Toxicol. Pathol., 63:419-431.

Neves, M.; Retameiro, A.C.B. and Tavares, A.L.F. (2020). Physical exercise and low-level laser therapy on the nociception and leukocyte migration of Wistar rats submitted to a model of rheumatoid arthritis. Lasers Med. Sci., 35(6):1277-1287. doi: 10.1007/s10103019-02905-2

Olajide, O.A.; Ajayi, A.M. and Wright, C.W. (2009). Anti inflammatory properties of cryptolepine. Phytothe Res., 23(10):1421-1425.

Rao, M.; Blane, K. and Zonneberg, M. (1985). One way analysis of variance: Version 1A (C). PC-STAT. University of Georgia. Athens, USA.

Sharifi-Rigi, A. and Heidarian, E. (2019). Protective and anti-inflammatory effects of silymarin on paraquat-induced nephrotoxicity in rats. J. Herbmed. Pharmacol., 8(1):28-34

Shavandi, M.; Moini, A. and Shakiba, Y. (2017). Silymarin (Livergol $($ ) decreases disease activity score in patients with rheumatoid arthritis: A non-randomized single-arm clinical trial. Iran J. Allergy Asthma Immunol., 16(2):99-106.

Sibilia, J. and Sordet, C. (2005). Le rituximab: Une biothérapie originale dans les maladies autoimmunes. Rev. Med. Interne., 26:485-500.

Stils, H.F. (2005). Adjuvants and antibody production: Dispelling the myths associated with freund's complete and other adjuvants. Inst. Lab. Ani. Resour. J., 46:280-293.

Subramoniam, A.; Madhavachandran, V. and Gangaprasad, A. (2013). Medicinal plants in the treatment of arthritis. Ann. Phytomed., 2(1):3-36.

Subramoniam, A. (2016). Food from plants with antiarthritic properties. Ann. Phytomed., 5(1):4-23.

Too, C.; Yahya, A.; Murad, S. and Dhaliwal, J. (2012). Smoking interacts with HLA-DRB1 shared epitope in the development of anti-citrullinated protein antibody-positive rheumatoid arthritis: Results from the malaysian epidemiological investigation of rheumatoid arthritis (MyEIRA). Arthritis Res. Ther., 14(2):R89.

Umar, S.; Zargan, J. and Umar, K. (2012). Modulation of the oxidative stress and inflammatory cytokine response by thymoquinone in the collagen induced arthritis in Wistar rats. Chem. Biol. Interact., 197:40-46.

Yoo, S.J. and Go E. Kim (2016). Roles of reactive oxygen species in rheumatoid arthritis pathogenesis. J. Rheum. Dis., 23(6):340-347.

Zholobenko, A.; Mouithys-Mickalad, A.; Modriansky, M.; Serteyn, D. and Franck, T. (2016). Polyphenols from Silybum marianum inhibit in vitro the oxidant response of equine neutrophils and myeloperoxidase activity. J. Vet. Pharmacol. Ther., 39(6):592-601. doi:10.1111/jvp.12319

Zhu, L.; Zhang, Z. and Xia, N. (2020). Anti-arthritic activity of ferulic acid in complete Freund's adjuvant (CFA)-induced arthritis in rats: JAK2 inhibition. Inflammopharmacol., 28(2):463-473. doi:10.1007/ s10787-019-00642-0

Citation M. S. Saber, H. I. Fahim, O. M. Ahmed, N. A. Ahmed and M. Abdel-Gabbar (2020). Assessment of the preventive effects of Silybum marianum (L.) Gaertn. seeds hydroethanolic extract and silymarin on complete Freund's adjuvantinduced arthritis in wistar rats. Ann. Phytomed., 9(2):172-182. http://dx.doi.org/10.21276/ap.2020.9.2.15 